OPEN ACCESS

Edited by:

Li Wang,

Chinese Academy of Sciences

(CAS), China

Reviewed by:

Lei Zhu,

Fudan University, China

Dan Cai,

Shanghai Normal University, China

*Correspondence:

Gang Dou

shotgun@163.com

Specialty section:

This article was submitted to Child and Adolescent Psychiatry,

a section of the journal

Frontiers in Psychiatry

Received: 24 June 2021 Accepted: 13 September 2021

Published: 08 October 2021

Citation:

Qian G, Li R, Yang W, Li R, Tian L and Dou G (2021) Sibling Jealousy and

Temperament: The Mediating Effect of Emotion Regulation in China During

COVID-19 Pandemic

Front. Psychiatry 12:729883. doi: 10.3389/fpsyt.2021.729883

\section{Sibling Jealousy and Temperament: The Mediating Effect of Emotion Regulation in China During COVID-19 Pandemic}

\author{
Guoying Qian ${ }^{1}$, Ruonan $\mathrm{Li}^{1}$, Wanqi Yang ${ }^{1}$, Ranran $\mathrm{Li}^{1}$, Li Tian ${ }^{2}$ and Gang Dou ${ }^{3 *}$ \\ ${ }^{1}$ College of Preschool Education, Capital Normal University, Beijing, China, ${ }^{2}$ School of Psychology, Capital Normal University, \\ Beijing, China, ${ }^{3}$ School of Education, Hubei University of Arts and Science, Xiangyang, China
}

This study aimed to examine first-born children's sibling jealousy and explore the relationships among first-born children's sibling jealousy, temperament, and emotion regulation in China during COVID-19 pandemic. The research hypotheses of this study are empirically examined through online and offline surveys. A sample of 304 two-child families from China participated in the study; the first-born children were aged between 1.17 and 7 years. The results indicated the following: (1) the older the first-born children and the greater the age difference between siblings, the lower the sibling jealousy. (2) Difficult temperament of first-born children could predict sibling jealousy significantly and positively, and emotion regulation could predict sibling jealousy negatively. (3) There was a partially mediating effect of emotion regulation between temperament and sibling jealousy. Compared with intermediate temperament, first-born children with difficult temperament had weaker emotion regulation and higher sibling jealousy. Overall, findings have important implications for psychological interventions for families of first-born children with difficult temperament.

Keywords: preschool first-born children, temperament, emotion regulation, sibling jealousy, COVID-19 pandemic

\section{INTRODUCTION}

The COVID-19 pandemic has greatly changed people's way of life and had a profound impact on people's psychology and behavior. In order to avoid the further spread of COVID-19, many countries, including China, have taken strict containment measures such as quarantine, closure of schools and public entertainment places, and social distancing $(1,2)$. During the normalization of the COVID-19 pandemic prevention and control in China, although the children have returned to school, they no longer go to public playgrounds and interest classes after school and during holidays as usual. Thus, they spend more time with their families.

Benefiting from the newly revised family planning policy, many Chinese families are transforming from one-child families into two-child families. And in the coming future, even more and more families with three children will appear. Due to the changes in family structure, sibling competition and sibling jealousy have become high-frequency issues of social concern, as well as practical problems faced by many young parents. The birth of the second child often causes some physical and psychological problems compared to that of the first $(3,4)$. Compared to the parents of two or more children, 
parents of only one child need to pay special attention to a new type of relationship that emerges after the birth of the second child, the sibling relationship, which was found in Previous studies can be influenced by the factors including sibling factors themselves (e.g., structural characteristics, temperament) and parent factors (parent-child relations, differential treatment, marital relationship, etc.) (5).

Sibling relationships might influence children's development through the mechanism of attachment, social learning, and social comparison (5). Siblings often develop a range of problematic behaviors due to jealousy (6-8). In the period of the normalization of the COVID-19 pandemic prevention and control, Children of two-child families are spending more time getting along with each other at home than before. Parents not only need to work, but also spend more time taking care of their children. They bear greater pressure and are more prone to anxiety and irritability, resulting in inappropriate treatment of their children (9). According to Volling et al. (8), first-born children may be jealous of their younger siblings because their parents spend more time with or take more care of the latter. Therefore, studying sibling jealousy in Chinese two-child families currently has special significance for the healthy development of children.

From a relationship perspective, jealousy refers to the emotion that an individual experiences when his or her important relationship with someone is threatened or faced with loss due to the intervention of a third party. Jealousy usually exists in the context of a social triangle formed by the jealous, beloved, and rival (10-12). As an emotion with a specific function, the purpose of jealousy is to prevent others from taking away the intimacy formed within relations, and the jealous person needs to take certain actions to protect this relationship (13). In family relationships, sibling jealousy refers to the complex social emotions that arise when the intimate relationship between a child and their parents is threatened by another child $(12,14)$. To restore intimacy, children may approach and seek the attention of their loved ones, become hostile to their siblings, or even prevent their siblings from having contact with their parents (15). At the psychological level, first-born children usually show emotions such as sadness, anxiety, and anger, and on the behavioral level, there will be manifestations such as seeking closeness, yelling at someone, degradation of behaviors, sleep changes, violent behavior, and decreased appetite (16-18). In families with multiple children, sibling jealousy is more likely to occur because of the relative reduction in the interaction time between the mother and one of the children, the unstable quality of attachment security, and the differentiated treatment of parents (18-20). Transactional models hold that the degree of sibling jealousy is primarily influenced by several factors, including individual characteristics, parental characteristics, family relations, and social environment (21). In this study, we focused on the influence of temperament and emotion regulation on sibling jealousy.

Researchers have found that girls' siblings are more jealous than boys' (22-24), and the age of the first child is negatively correlated with jealousy (25). As far as siblings are concerned, different gender combinations and age differences provide a unique family background for children's social adaptation process in China (5) and are also an important factor for siblings to compete for the limited resources of their parents (26). However, studies have found that the age gap and gender combination are not associated with sibling jealousy $(24,27)$. Therefore, it is necessary to study the influence of age, gender, gender combination and age gap on the jealousy of first-born children in the Chinese test group.

The temperament of children refers to the individual differences in the emotion, activity level, and attention of children in the early stage, and it is the external manifestation of children's response to the surrounding stimulation. It is more of an innate factor that is less affected by the environment. The temperament of young children seems to be the key factor in understanding the difficulties children face in the transition to sibling relationships and whether sibling jealousy appears in early childhood (28). Bad-tempered children are more likely to protest their mothers taking care of the younger siblings after their birth (29). Children with difficult temperaments tend to be less self-soothing, show more negative emotions such as anger, and are reluctant to take care of younger siblings $(30,31)$. First-born children with difficult temperaments show clinginess, withdrawal, and problems with eating and sleeping during the transition to sibling relationships (31-35).

Emotion regulation is the internal and external process of regulating, evaluating, and managing emotional responses to achieve expected goals, such as controlling emotional expression and effectively managing negative emotions (36). It is also a process in which individuals exert influence on the occurrence, experience, and expression of emotions (37). Children's emotion regulation includes the process of emotion regulation and emotional instability (38). The effect of emotion regulation on jealousy has been confirmed by many researchers (39-41). For example, researchers have found that the use of diversion strategies can reduce the level of pain after jealousy, which shows that effective emotion regulation strategies can reduce negative emotional experiences associated with jealousy (42). In the "More Fun with Sisters and Brothers (MFWSB)" program, researchers have asked children aged 4-8 to learn strategies (e.g., recognition, monitoring, evaluation, and correction) to improve their emotional and social abilities. The results showed that the emotion regulation ability and sibling relationship of the experimental group improved (43). Some researchers also believe that the first child's emotional regulation ability is higher than that of the second child. At the same time, jealousy is more implicit and flexible $(27,40)$.

There are some commonalities in the development of children's emotion regulation, but there are still some significant individual differences. One of these inherent differences is temperament, defined by Rothbart and Bates (44). Rothbart and Bates believe that temperament is a biological basis that leads to differences in individual behavior, and it will be affected by heredity, maturity, and experience (44). Murphy's research has found that children with more negative emotions and low control do not show stronger jealousy, which he believes is related to the individual's good emotion regulation ability (45). In early childhood, as a part of the temperament, children's emotions 


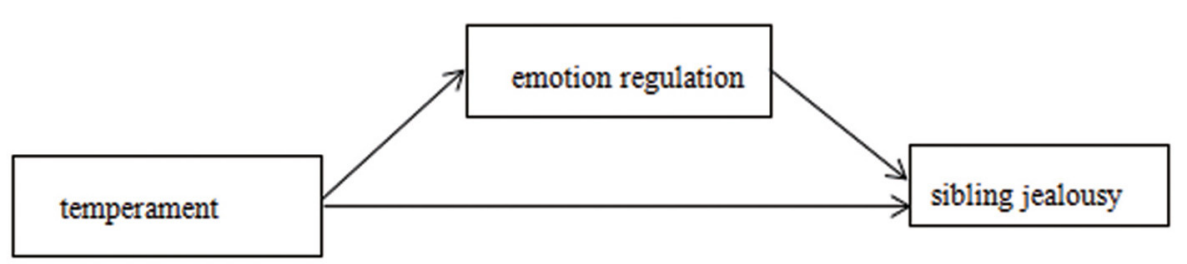

FIGURE 1 | The proposed mediation model.

and emotion regulation are still affected by individual inherent genetic factors (46). Therefore, the abnormal development of different levels of emotion regulation displayed by children can be traced back to differences in children's inherent temperament (47). Temperament can predict and hinder the development of young children's emotion regulation (48).

Based on the above research, we hypothesize that temperament and emotion regulation can jointly predict sibling jealousy and that emotion regulation plays a mediating role in temperament and sibling jealousy (see Figure 1).

\section{METHODS}

\section{Participants}

This study was approved by the Research Ethics Committee of the first author's institution. Online and offline surveys were conducted from January to March, 2021. 304 two-child families were randomly recruited from Hubei, Hunan, Jiangxi, and Beijing. The questionnaire was completed by the mothers of the children. There were 149 male and 155 female firstborns, ranging from 1.17 to 7 years of age $(M=5.33, S D=1.22)$, and their younger siblings, including 162 males and 142 females, ranging in from 1.17 to 6.17 years of age $(M=2.12, S D=1.32)$. The average age gap between firstborns and their younger siblings was 3.29 years. Of the families, $70.7 \%$ were three-generation families, and $84.5 \%$ of the parents were the main caregivers. Families with a combined income of over $\$ 10,000$ accounted for $86.2 \%$ of the total.

\section{Measures}

\section{First-Born Children's Sibling Jealousy}

A revised Chinese version of the Children Sibling Jealousy Questionnaire developed by Kahriman and Kanak (23) and Chen and Yang (49), was used in this study. It consists of 16 items. A five-point scale, ranging from "my child hardly ever does it" to "my child always does it," was used to estimate the current behaviors and emotions of the first-born child by their main caregiver. The higher the score, the higher the level of sibling jealousy. Cronbach's $\alpha$ for the scale was 0.93 .

\section{Temperament Scale}

The Children's Temperament Questionnaire $(50,51)$ consisted of 72 items belonging to nine subscales: reaction threshold, avoidance, adaptability, activity level, rhythm, reaction intensity, emotional nature, persistence, and the degree of distraction. The scale adopted a seven-point evaluation, ranging from " 1 " (never) to "7" (always) of the firstborn children's daily behaviors, which were assessed by mothers. Cronbach's $\alpha$ for the scale was 0.94 .

\section{Emotion Regulation}

The Emotion Regulation Checklist (ERC) was developed by Shields and Cicchetti (52) and revised by Chang et al. (53) from Hong Kong as well as Chinese mainland scholars (52-54). It consists of 24 items divided into two subscales: (1) emotional instability, which was used to assess children's tendency to be volatile, unstable, and have abnormal negative emotions. The higher the score, the more unstable the mood (52); (2) emotional regulation, which assessed children's ability to respond to emotion regulation in different situations, including the appropriateness of emotional expression, empathy, and emotional self-awareness. The higher the scores, the higher the emotion regulation. The questionnaire was scored on a sevenpoint scale ranging from " 1 " (never) to " 7 " (almost always). Cronbach's $\alpha$ for the scale was 0.92 .

\section{Data Analysis}

Data were analyzed using SPSS 22.0. Pearson correlation analysis and the Marco PROCESS (Model 4) (55) were used to analyze the relationships among sibling jealousy, temperament, and emotion regulation.

\section{RESULTS}

\section{Sibling Jealousy of First-Born Children}

A univariate regression analysis was used to investigate the predictability of the age of the first child on the jealousy level toward the siblings. The results showed that $R^{2}=0.02$, indicating that the age of the first child could effectively explain a $2 \%$ variation in the jealousy level of the first child toward the sibling. The standardized regression $\beta=-0.15, t=-2.61, p<0.05$, reaching a significant level, indicated that the greater the age of the first child, the lower the sibling jealousy level, and the unary regression analysis was used to investigate the predictability of the age difference between the first and second children on the sibling jealousy level of the first-born children. In general, $R^{2}=$ 0.04 , which meant that the age difference could effectively explain a $4 \%$ variation in the sibling jealousy level of the first child. The standardized regression $\beta=-0.21, t=-3.62, p<0.01$, reaching a significant level, indicated that the greater the age difference, the lower the sibling jealousy level of the first child.

A univariate analysis of variance (UNIANOVA) with firstborn children's sex (two levels) and second-born children's sex 
TABLE 1 | Pearson correlation coefficients of the study variables $(n=304)$.

\begin{tabular}{|c|c|c|c|c|}
\hline & $\mathbf{M} \pm \mathrm{SD}$ & 1 & 2 & 3 \\
\hline 1. Temperament & $2.79 \pm 1.36$ & - & & \\
\hline 2. Emotion regulation & $4.07 \pm 0.50$ & $0.34^{\star *}$ & - & \\
\hline 3. Sibling jealousy & $1.83 \pm 0.66$ & $-0.19^{\star \star}$ & $-0.21^{\star \star}$ & - \\
\hline
\end{tabular}

${ }^{\star \star} p<0.01$

(two levels) as factor variables, first-born children's age and the age difference as controlling variables, and the sibling jealousy score as the dependent variable was conducted. There was a significant main effect of the second-born children's sex, $F_{(1,303)}$ $=6.29, p<0.05, \eta_{p}^{2}=0.02$, and the jealousy score of the male second-born children $(M=1.92)$ was significantly higher than that of the female second-born children $(M=1.73)$. There were no significant main effects of the first-born children's sex $\left[F_{(1,303)}\right.$ $\left.=0.04, p>0.05, \eta_{p}^{2}=0.00\right]$ and first-born children's sex $\times$ second-born children's sex interaction $\left[F_{(1,303)}=0.10, p>0.05\right.$, $\left.\eta_{p}^{2}=0.00\right]$ on siblings' jealousy scores.

\section{Sibling Jealousy, Temperament, and Emotion Regulation}

There were four child temperaments: difficult, slow-to-warm, easy, and mixed (51). We set dummy variables for each temperament type, with X1 for "easy to difficult," X2 for "slowto-warm-to-difficult," and X3 for "mixed to difficult." Pearson correlation analysis was conducted to examine the relationships among sibling jealousy, temperament, and emotion regulation. For the first-born children, sibling jealousy was negatively related to temperament $(r=-0.19, p<0.01)$ and emotion regulation $(r$ $=-0.21, p<0.01)$, and temperament was positively related to emotion regulation $(r=0.34, p<0.01)$ (see Table 1 ).

Based on the correlation analysis results, Model 4 was used to test the mediating effect of emotion regulation on the relationship between temperament and sibling jealousy. Controlling for the gender combination, age difference, family structure, main caregivers, and familial income of the two children, the results (see Table 2) showed that the direct path from X2 and X3 to sibling jealousy ( $\beta=-0.24, p<0.05 ; \beta=-0.39, p<0.001)$, in the absence of emotion regulation, was significant. Emotion regulation was significantly associated with $\mathrm{X} 1(\beta=0.56, p<$ $0.001), \mathrm{X} 2(\beta=0.33, p<0.001), \mathrm{X} 3(\beta=0.39, p<0.001)$, and sibling jealousy $(\beta=-0.25, p<0.01)$. However, only X3 significantly predicted sibling jealousy $(\beta=-0.29, p<0.001)$. Therefore, compared with intermediate temperament, emotion regulation partially mediated the relationship between difficult temperament and sibling jealousy.

To assess the size of the indirect effect and confidence intervals (CIs), a bootstrap procedure was applied. For the indirect effect, 95 percent bias-corrected accelerated CIs without "zero" indicated a significant mediation effect. We generated 5,000 bootstrap samples. The indirect effect of temperament on sibling jealousy mediated by emotion regulation $[\mathrm{ab}=-0.15, S E=0.06$, $95 \%$ CI $(-0.26,-0.06)]$ was significant. The mediation effect accounted for $38.68 \%$ of the total effect. The $95 \%$ CI did not contain zero, showing that temperament exerted a significant indirect effect on sibling jealousy via emotion regulation.

\section{DISCUSSION}

The present research was framed during the normalization of the COVID-19 pandemic, providing unique empirical evidence regarding sibling jealousy and the relationships among first-born children's sibling jealousy, temperament, and emotion regulation. Major results showed that, for first-born children between the ages of 1.17 and 7, the older they are and the greater the age difference between them and the second children, the lower their sibling jealousy. There were no significant main effects for the sex difference in sibling jealousy, which is consistent with previous studies $(5,25,27)$. The sibling jealousy of male second-born children was significantly higher than that of females, which was inconsistent with the results of previous studies (22-24). A possible reason was that, in the socio-cultural context of China, older brothers or sisters should give way to younger ones, so the sex difference in the jealousy of the first-born children was not significant, while the male second children had a stronger attachment to their mothers, so their jealousy was higher than that of the females.

Furthermore, this study found that difficult temperament could positively predict sibling jealousy, and emotion regulation was a negative predictor. This result was consistent with previous studies that showed that first-born children with difficult temperaments exhibited more jealous behaviors such as negative emotions, attachment issues, withdrawal, as well as eating and sleeping problems during the transition to sibling relationships $(30-35,56,57)$. Children with low emotion regulation who were in a jealous situation would report a higher level of sibling jealousy because of their inability to regulate their own jealousy response (57). Effective emotion regulation could reduce sibling jealousy $(27,42,43)$. Although the triadic laboratory paradigm was mainly used to measure sibling jealousy, that is, to design a jealous situation in which a mother or father interacted with one child while ignoring the other, the experimental object was the neglected children, and researchers observed the jealousy emotion and behavior dissonance that were shown in that respective context. In this study, we used a questionnaire to survey the sibling jealousy of first-born children, which involved the first child's anxiety, distress, sadness, anger, bad sleep patterns and eating habits, degradation of behaviors, and attacking the sibling after the birth of the second child. These emotional 
TABLE 2 | Testing the mediation effect of emotion regulation on sibling jealousy.

\begin{tabular}{|c|c|c|c|c|c|c|}
\hline \multirow[t]{2}{*}{ Predictors (IV) } & \multicolumn{2}{|c|}{ Model 1 (DV: sibling jealousy) } & \multicolumn{2}{|c|}{ Model 2 (DV: emotion regulation) } & \multicolumn{2}{|c|}{ Model 3 (DV: sibling jealousy) } \\
\hline & $\beta$ & $T$ & $\beta$ & $t$ & $\beta$ & $t$ \\
\hline Temperament X1 & -0.31 & -1.54 & 0.56 & $3.77^{\star \star \star}$ & -0.16 & -0.83 \\
\hline Temperament X2 & -0.24 & $-2.02^{\star}$ & 0.33 & $3.74^{\star \star \star}$ & -0.15 & -1.31 \\
\hline Temperament X3 & -0.39 & $-4.84^{\star \star \star}$ & 0.39 & $6.57^{\star \star \star}$ & -0.29 & $-3.42^{\star \star \star}$ \\
\hline Emotion regulation & & & & & -0.25 & $-3.31^{\star \star}$ \\
\hline $\mathrm{R}^{2}$ & $0.149 .55^{\star \star \star}$ & $0.1611 .16^{\star \star \star}$ & $0.1710 .05^{\star \star \star}$ & & & \\
\hline $\mathrm{F}$ & & & & & & \\
\hline
\end{tabular}

$I V$, Independent Variable; DV, Dependent Variable; ${ }^{\star} p<0.05$, ${ }^{* \star} p<0.01$, and ${ }^{\star \star *} p<0.001$.

expressions and behavior performances were consistent with the measurement of sibling jealousy in experimental research. Therefore, the conclusion drawn from the questionnaire survey on Chinese samples was consistent with Western research.

Moreover, this study was the first to explore the mediating role of emotion regulation between temperament and sibling jealousy. As a complex social emotion $(12,14)$, jealousy is closely related to emotion regulation, while in early childhood, the emotion regulation of children is a part of temperament $(46,47)$, which, in turn, predicts their emotion regulation (48). Compared with children with intermediate temperament, firstborn children with difficult temperament had a weaker emotion regulation ability and higher sibling jealousy. out of 4 domains (i.e., rhythm, avoidance, adaptability, and emotional essence) that were evaluated, difficult children revealed low-scores in at least three domains. They had irregular daily routines, including issues with eating, drinking, sleeping, urinating, and defecating; therefore, children with low temperament rhythms were more likely to be in a changing environment, which was detrimental to their emotional stability. First-born children with an avoidance tendency and poor adaptability to the new environment might be afraid of unfamiliar people and the changes in the environment caused by the new event of the second sibling's birth. Lower scores on emotional nature indicated that first-born children were often in a negative mood, which aggravated the frequency and degree of sibling jealousy occurrence. Therefore, during the normalization of the pandemic, we need to pay special attention to difficult children to help them improve their emotion regulation ability. This will have the effect of reducing sibling jealousy and maintaining a good level of mental health.

This study statically examined the relationships among temperament, emotion regulation, and sibling jealousy during COVID-19 pandemic, but failed to longitudinally investigate the interaction mechanism between siblings in the formation of sibling jealousy and also lacked research on the changes in parenting styles before and after the birth of the second child. Therefore, future research needs to further carry out big data tracking research and in-depth investigations of the interaction mechanism between siblings and that of the parental rearing style and sibling jealousy in different periods. This study used a questionnaire to assess the jealousy toward siblings in firstborn children. In the future, it will be necessary to use the triad laboratory paradigm, interviews, and questionnaires to evaluate sibling jealousy more comprehensively and objectively from the perspective of both parents and children.

\section{DATA AVAILABILITY STATEMENT}

The original contributions presented in the study are included in the article/supplementary material, further inquiries can be directed to the corresponding author/s.

\section{ETHICS STATEMENT}

The studies involving human participants were reviewed and approved by Scientific Research Ethics Committee of School of preschool education, Capital Normal University. The patients/participants provided their written informed consent to participate in this study.

\section{AUTHOR CONTRIBUTIONS}

GQ designed the project and supervised the data collection. WY, GQ, and GD collected and analyzed the data. GQ and GD wrote the manuscript with input from all other authors. All authors contributed to the article and approved the submitted version.

\section{FUNDING}

This study was supported by the Project of Municipal Science and Technology Commission of Beijing (20530290022), Capacity Building for Sci-Tech Innovation-Fundamental Scientific Research Funds (20530290062) and Scientific Research Cultivation Fund of Hubei University of Arts and Science (2017kypy025).

\section{ACKNOWLEDGMENTS}

We thank the parents of the children and the principals of the kindergarten who helped us gather data for this study. 


\section{REFERENCES}

1. Brooks SK, Webster RK, Smith LE, Woodland L, Wessely S, Greenberg N, et al. The psychological impact of quarantine and how to reduce it: rapid review of the evidence. Lancet. (2020) 395:912-20. doi: 10.1016/S0140-6736(20)30460-8

2. Galea S, Merchant RM, Lurie N. The mental health consequences of COVID19 and physical distancing: the need for prevention and early intervention. JAMA Intern Med. (2020) 180:817-18. doi: 10.1001/jamainternmed.2020.1562

3. Stewart RBJ. The Second Child: Family Transition and Adjustment. Thousand Oaks, CA: SAGE Publications, Inc (1990).

4. Qian GY, Zheng W, Wang W, Chen X, Li LF, Yang WQ, et al. Relationship between social development and psychological adaptation of the first-born children in china. Curr Psychol. (2019) 10:1-8. doi: 10.1007/s12144-019-00576-4

5. Chen BB, Zhao YH, Han W, Wang Y, Wu J, Yue X, et al. Sibling relationships: forms, causes and consequences (in Chinese). Adv Psychol Sci. (2017) 25:216878. doi: 10.3724/SP.J.1042.2017.02168

6. Kowal A, Kramer L, Krull JL, Crick NR. Children's perceptions of the fairness of parental preferential treatment and their socioemotional well-being. J Fam Psychol. (2002) 16:297-306. doi: 10.1037/0893-3200.16.3.297

7. Kowal AK, Krull JL, Kramer L. Shared understanding of parental differential treatment in families. Soc Dev. (2006) 15:276-95. doi: 10.1111/j.1467-9507.2006.00341.x

8. Volling BL, Yu T, Gonzalez R, Kennedy DE, Rosenberg L, Oh W. Children's responses to mother-infant and father-infant interaction with a baby sibling: Jealousy or joy? J Fam Psychol. (2014) 28:634-44. doi: 10.1037/a0037811

9. Qian G, Mei J, Tian L, Dou G. Assessing Mothers' Parenting Stress: Differences Between One- and Two-Child Families in China. Front Psychol.(2021)11:609715. doi: 10.3389/fpsyg.2020.609715

10. Parrott WG. Mood induction and instructions to sustain moods: a test of the subject compliance hypothesis of mood congruent memory. Cogn Emot. (1991) 5:41-52. doi: 10.1080/02699939108411022

11. Salovey P, Rodin J. Provoking jealousy and envy: domain relevance and self-esteem threat. J Soc Clin Psychol. (1991) 10:395-413. doi: 10.1521/jscp.1991.10.4.395

12. White GL, Mullen PE. Jealousy: Theory, Research, and Clinical Strategies. New York, NY: Guilford Press (1989).

13. Chung M, Harris CR. Jealousy as a specific emotion: the dynamic functional model. Emot Rev. (2018) 10:272-87. doi: 10.1177/1754073918795257

14. Mathes EW, Adams HE, Davies RM. Jealousy: loss of relationship rewards, loss of self-esteem, depression, anxiety, and anger. J Pers Soc Psychol. (1985) 48:1552-61. doi: 10.1037/0022-3514.48.6.1552

15. Campos JJ, Walle EA, Dahl A. What is missing in the study of the development of jealousy. In: Hart SL, Legerstee M, editors. Handbook of Jealousy: Theory, Research, and Multidisciplinary Approaches. Hoboken, NJ: Wiley-Blackwell (2010). p. 312-28.

16. Bradley BS. Jealousy in infant-peer trios: from narcissism to culture. In: Hart SL, Legerstee M, editors. Handbook of Jealousy: Theory, Research, and Multidisciplinary Approaches. Hoboken, NJ: Wiley-Blackwell (2010). p. 192234.

17. Draghi LR. Parental reports of jealousy in early infancy: Growing tensions between evidence and theory. In: Hart SL, Legerstee M, editors. Handbook of Jealousy: Theory, Research, and Multidisciplinary Approaches. Hoboken, NJ: Wiley-Blackwell (2010). p. 235-66.

18. Hart SL. A theoretical model of the development of jealousy: Insight through inquiry into jealousy protest. In: Hart SL, Legerstee M, editors. Handbook of Jealousy: Theory, Research, and Multidisciplinary Approaches. Hoboken, NJ: Wiley-Blackwell (2010). p. 329-61.

19. Dunn J, Mcguire S. Sibling and peer relationships in childhood. J Child Psychol Psychiatry. (1992) 33:67-105. doi: 10.1111/j.1469-7610.1992.tb00859.x

20. Hart W, Tortoriello GK, Richardson K, Adams J. S/he's taken: effects of grandiose and vulnerable narcissism on responses to relationship threats from rivals. J Individ Differ. (2018) 39:212-19. doi: 10.1027/1614-0001/a000266

21. Volling BL, Kennedy DE, Jackey LMH. The development of sibling jealousy. In: Hart SL, Legerstee M, editors. Handbook of Jealousy: Theory, Research, and Multidisciplinary Approaches. Hoboken, NJ: Wiley-Blackwell (2010). p. 387-417.
22. Deutz MHF, Lansu TAM, Cillessen AHN. Children's observed interactions with best friends: associations with friendship jealousy and satisfaction. Soc Dev. (2015) 24:39-56. doi: 10.1111/sode.12080

23. Kahriman I, Kanak M. The examination of the knowledge, attitudes and practices of expectant mothers towards sibling jealousy and the jealousy behaviors in their children. Res Peda. (2018) 8:132-44. doi: 10.17810/2015.79

24. Thompson JA, Halberstadt AG. Children's accounts of sibling jealousy and their implicit theories about relationships. Soc Dev. (2008) 17:488511. doi: 10.1111/j.1467-9507.2007.00435.x

25. Dagcioglu BF. The effects of the new baby on the older sibling. Ank Med J. (2018) 18:286-99. doi: 10.17098/amj.461653

26. Bonisoli-Alquati A, Boncoraglio G, Caprioli M, Saino N. Birth order, individual sex and sex of competitors determine the outcome of conflict among siblings over parental care. Proc Biol Sci B Biol Sci. (2011) 278:12739. doi: 10.1098/rspb.2010.1741

27. Miller AL, Volling BL, McElwain NL. Sibling jealousy in a triadic context with mothers and fathers. Soc Dev. (2000) 9:433-57. doi: 10.1111/1467-9507.00137

28. Dunn J, Brown J, Slomkowski C, Tesla C, Youngblade L. Young children's understanding of other people's feelings and beliefs: Individual differences and their antecedents. Child Dev. (1991) 62:1352-66. doi: 10.2307/1130811

29. Kendrick MJ, Craig KD, Lawson DM, Davidson PO. Cognitive and behavioral therapy for musical-performance anxiety. J Consult Clin Psychol. (1982) 50:353-62. doi: 10.1037/0022-006X.50.3.353

30. Dunn J, Kendrick C. Temperamental differences, family relationships, and young children's response to change within the family. Ciba Found Symp. (1982) 89:87-105. doi: 10.1002/9780470720714.ch6

31. Volling BL, Herrera C, Poris MP. Situational affect and temperament implications for sibling caregiving. Infant Child Dev. (2004) 13:17383. doi: $10.1002 /$ icd. 360

32. Kendrick C, Dunn J. Protest or pleasure? The response of first-born children to interactions between their mothers and infant siblings. J Child Psychol Psychiatry. (1982) 23:117-29. doi: 10.1111/j.1469-7610.1982.tb00057.x

33. Gallagher KC. Does child temperament moderate the influence of parenting on adjustment? Dev Rev. (2002) 22:62343. doi: 10.1016/S0273-2297(02)00503-8

34. Kolak AM, Volling BL. Coparenting moderates the association between firstborn children's temperament and problem behavior across the transition to siblinghood. J Fam Psychol. (2013) 27:355-64. doi: 10.1037/a0032864

35. Pluess M, Belsky J. Differential susceptibility to parenting and quality child care. Dev Psychol. (2010) 46:379-90. doi: 10.1037/a0015203

36. Thompson RA. Emotion regulation: a theme in search of definition. Monogr Soc Res Child Dev. (1994) 59:25-52. doi: 10.1111/j.1540-5834.1994.tb01276.x

37. Gross JJ. Emotion regulation: affective, cognitive, and social consequences. Psychophysiology. (2002) 39:281-91. doi: 10.1017/S0048577201393198

38. Morris AS, Criss MM, Silk JS, Houltberg BJ. The impact of parenting on emotion regulation during childhood and adolescence. Child Dev Perspect. (2017) 11:233-8. doi: 10.1111/cdep.12238

39. Volling BL, McElwain NL, Miller AL. Emotion regulation in context: the jealousy complex between young siblings and its relations with child and family characteristics. Child Dev. (2002) 73:581-600. doi: 10.1111/1467-8624.00425

40. Hart SL, Behrens KY. Affective and behavioral features of jealousy protest: associations with child temperament, maternal interaction style, and attachment. Infancy. (2013) 18:369-99. doi: 10.1111/j.1532-7078.2012.00123.x

41. Mikulincer M, Shaver PR, Pereg D. Attachment theory and affect regulation: the dynamics, development, and cognitive consequences of attachment-related strategies. Motiv Emot. (2003) 27:77-102. doi: 10.1023/A:1024515519160

42. Crockenberg SC, Leerkes EM. Infant and maternal behaviors regulate infant reactivity to novelty at 6 months. Dev Psychol. (2004) 40:112332. doi: $10.1037 / 0012-1649.40 .6 .1123$

43. Kennedy DE, Kramer L. Improving emotion regulation and sibling relationship quality: the more fun with sisters and brothers program. Fam Relat. (2008) 57:567-78. doi: 10.1111/j.1741-3729.2008.00523.x

44. Rothbart MK, Bates JE. Temperament. In: Damon W (Series Ed.) and Eisenberg N (Vol. Ed.). Social, Emotional, and Personality Development: Handbook of Child Psychology. Vol. 3. New York, NY: Wiley (1998). p. 105-76. 
45. Murphy TP, McCurdy K, Jehl B, Rowan M, Larrimore K. Jealousy behaviors in early childhood: associations with attachment and temperament. Int J Behav Dev. (2020) 44:266-72. doi: 10.1177/0165025419877974

46. Goldsmith HH, Buss KA, Lemery KS. Toddler and childhood temperament: expanded content, stronger genetic evidence, new evidence for the importance of environment. Dev Psychol. (1997) 33:891-905. doi: 10.1037/0012-1649.33.6.891

47. Liu W, Yu TX, Liu F. The mechanisms of brain connectivity and interventions of emotion regulation deficits of maltreated children (in Chinese). J Liaoning Norm Univ (Soc Sci Ed). (2019) 4:1-8. doi: 10.16216/j.cnki.lsxbwk.201904001

48. Séguin DG, MacDonald B. The role of emotion regulation and temperament in the prediction of the quality of social relationships in early childhood. Early Child Dev Care. (2018) 188:1147-63. doi: 10.1080/03004430.2016.1251678

49. Chen JY, Yang LZ. A study on the structure of children's jealousy from 36 years old (in Chinese). J Liaoning Norm Univ (Soc Sci Ed). (2014) 4:62-6. doi: 10.16187/j.cnki.issn1001-4918.2017.04.01

50. Chess S, Thomas A. Temperament and the parent-child interaction. Pediatr Ann. (1977) 6:574-82. doi: 10.3928/0090-4481-19770901-07

51. Zhang YQ, Lin W, Luo YZ. An assessment on temperamental characteristics of children aged from 3 to 6 years old from their teachers (in Chinese). Chin J Clin Psychol. (1994) 2:211-4.

52. Shields A, Cicchetti D. Emotion regulation among school-age children: the development and validation of a new criterion Q-sort scale. Dev Psychol. (1997) 33:906-16. doi: 10.1037/0012-1649.33.6.906

53. Chang L, Schwartz D, Dodge KA, McBride-Chang C. Harsh parenting in relation to child emotion regulation and aggression. J Fam Psychol. (2003) 17:598-606. doi: 10.1037/0893-3200.17.4.598

54. Li XW, Yang QQ, Zou H. Mother and father reported reactions to children's negative emotions and children's emotion regulation ability (in Chinese). Psychol Dev Educ. (2017) 4:385-93.
55. Hayes AF, Scharkow M. The relative trustworthiness of inferential tests of the indirect effect in statistical mediation analysis: does method really matter? Psychol Sci. (2013) 24:1918-27. doi: 10.1177/09567976134 80187

56. McElwain NL, Volling BL. Attachment security and parental sensitivity during infancy: associations with friendship quality and false-belief understanding at age 4. J Soc Pers Relat. (2004) 21:639-67. doi: 10.1177/0265407504045892

57. Kolak AM, Volling BL. Sibling jealousy in early childhood: longitudinal links to sibling relationship quality. Infant Child Dev. (2011) 20:21326. doi: $10.1002 /$ icd. 690

Conflict of Interest: The authors declare that the research was conducted in the absence of any commercial or financial relationships that could be construed as a potential conflict of interest.

Publisher's Note: All claims expressed in this article are solely those of the authors and do not necessarily represent those of their affiliated organizations, or those of the publisher, the editors and the reviewers. Any product that may be evaluated in this article, or claim that may be made by its manufacturer, is not guaranteed or endorsed by the publisher.

Copyright (C) 2021 Qian, Li, Yang, Li, Tian and Dou. This is an open-access article distributed under the terms of the Creative Commons Attribution License (CC BY). The use, distribution or reproduction in other forums is permitted, provided the original author(s) and the copyright owner(s) are credited and that the original publication in this journal is cited, in accordance with accepted academic practice. No use, distribution or reproduction is permitted which does not comply with these terms. 